\title{
Financial Statement for the Eastern Economic Association for Fiscal Years 2006-2007 and 2007-2008
}

\begin{tabular}{|c|c|c|c|}
\hline & $2007 / 2008$ & $2006 / 2007$ & Change \\
\hline Opening balance & $\$ 21,580.18$ & $\$ 80,459.27$ & $-\$ 58,879.09$ \\
\hline \multicolumn{4}{|l|}{ Revenue and income } \\
\hline \multicolumn{4}{|l|}{ Revenue } \\
\hline Membership dues & $\$ 27,820.00$ & $\$ 27,295.00$ & $\$ 525.00$ \\
\hline Library subscriptions & $\$ 720.00$ & $\$ 6,865.00$ & $-\$ 6,145.00$ \\
\hline Conference registrations & $\$ 35,145.00$ & $\$ 40,385.00$ & $-\$ 5,240.00$ \\
\hline Paper submission fees & $\$ 10,655.00$ & $\$ 20,890.00$ & $-\$ 10,235.00$ \\
\hline Conference booths and ads & $\$ 8,850.00$ & $\$ 7,150.00$ & $\$ 1,700.00$ \\
\hline Sales of luncheon tickets & $\$ 920.00$ & $\$ 1,990.00$ & $-\$ 1,070.00$ \\
\hline Other (royalties, misc, EEJ) & $\$ 9,661.60$ & $\$ 3,783.51$ & $\$ 5,878.09$ \\
\hline Total revenue & $\$ 93,771.60$ & $\$ 108,358.51$ & $-\$ 14,586.91$ \\
\hline \multicolumn{4}{|l|}{ Income } \\
\hline Interest (BONY)/Sweep return & $\$ 118.42$ & $\$ 1,467.00$ & \\
\hline Total income & $\$ 118.42$ & $\$ 1,467.00$ & $-\$ 1,348.58$ \\
\hline Total revenue and income & $\$ 93,890.02$ & $\$ 109,825.51$ & $-\$ 15,935.49$ \\
\hline \multicolumn{4}{|l|}{ Expenses } \\
\hline Eastern Economic Journal & $\$ 31,891.34$ & $\$ 58,882.22$ & $-\$ 26,990.88$ \\
\hline Headquarters & $\$ 18,500.00$ & $\$ 25,000.00$ & $-\$ 6,500.00$ \\
\hline Eckstein Prize Award & $\$ 1,349.93$ & $\$ 1,349.93$ & $\$ 0.00$ \\
\hline Credit card fees & $\$ 2,270.27$ & $\$ 3,453.49$ & $-\$ 1,183.22$ \\
\hline Legal fees & $\$ 0.00$ & $\$ 943.25$ & $-\$ 943.25$ \\
\hline CPA fees & $\$ 1,675.00$ & $\$ 1,600.00$ & $\$ 75.00$ \\
\hline Bank fees & $\$ 63.74$ & $\$ 116.69$ & $-\$ 52.95$ \\
\hline Insurance D\&O & $\$ 1,050.00$ & $\$ 1,000.00$ & $\$ 50.00$ \\
\hline Insurance liability & $\$ 764.03$ & $\$ 534.82$ & $\$ 229.21$ \\
\hline Hotel deposits & $\$ 0.00$ & $\$ 0.00$ & $\$ 0.00$ \\
\hline Conference expense & $\$ 53,902.99$ & $\$ 72,299.27$ & $-\$ 18,396.28$ \\
\hline Honoraria & $\$ 0.00$ & $\$ 4,500.00$ & $-\$ 4,500.00$ \\
\hline Miscellaneous & $\$ 0.00$ & $\$ 374.86$ & $-\$ 374.86$ \\
\hline Total expenses & $\$ 111,467.30$ & $\$ 170,054.53$ & $-\$ 58,587.23$ \\
\hline Revenue + Income-Expenses & $-\$ 17,577.28$ & $-\$ 60,229.02$ & $\$ 42,651.74$ \\
\hline \multicolumn{4}{|l|}{ Transfers to/from operations } \\
\hline \multicolumn{4}{|l|}{ Withdrawal from savings } \\
\hline To Vanguard & $\$ 0.00$ & $\$ 0.00$ & $\$ 0.00$ \\
\hline From Dime CD & $\$ 0.00$ & $\$ 0.00$ & $\$ 0.00$ \\
\hline To Union State CD & $\$ 0.00$ & $\$ 0.00$ & $\$ 0.00$ \\
\hline From Sweep account & $\$ 23.49$ & $\$ 0.00$ & $\$ 23.49$ \\
\hline Total transfers & $\$ 23.49$ & $\$ 0.00$ & $\$ 23.49$ \\
\hline Closing balance & $\$ 4,026.39$ & $\$ 20,230.25$ & $-\$ 16,203.86$ \\
\hline \multicolumn{4}{|l|}{ Other assets } \\
\hline \multicolumn{4}{|l|}{$C D$} \\
\hline Value & $\$ 12,508.45$ & $\$ 11,903.32$ & \\
\hline \multicolumn{4}{|l|}{ Vanguard } \\
\hline Acct value & $\$ 96,723.94$ & $\$ 111,337.59$ & \\
\hline Total assets & $\$ 113,258.78$ & $\$ 143,471.16$ & \\
\hline
\end{tabular}

